\title{
Evaluation of Flexural Strength of Polymethylmethacrylate Denture Base Resin Incorporated with Alkali and Heat-Treated Teak Wood Fibers and Ultra High Molecular Weight Polyethylene Fibers
}

\author{
Puja Harie Priya M.S. ${ }^{1}$, Brintha Jei J.2, Murugesan Krishnan³ ${ }^{3}$, Muthukumar Balasubramanium ${ }^{4}$ \\ ${ }^{1}$ Department of Prosthodontics and Crown \& Bridge, Ragas Dental College and Hospital, Uthandi, Chennai, \\ Tamil Nadu, India, 2, 3, 4 Department of Prosthodontics and Crown \& Bridge \\ SRM Dental College, Ramapuram, Chennai, Tamil Nadu, India.
}

\section{ABSTRACT}

\section{BACKGROUND}

Polymethyl-methacrylate (PMMA) resin is the most commonly used denture base material which satisfies colour stability, aesthetic demands, accurate fit, affordable cost, and ease in manipulation. The common disadvantages are incomplete flow, impact strength, transverse strength and fatigue resistance. The fracture of denture base is mainly due to flexural fatigue failure which can be minimised by reinforcing with various artificial and natural fibres. There are very few studies which have incorporated natural fibres to enhance the strength of PMMA resin. So, in this study both natural and artificial fibres were used to enhance the property and find the best fibres to strengthen the denture base.

\section{METHODS}

A total of 80 samples were prepared using a standardized stainless steel metal die and these samples were grouped into Group A as control group, Group B PMMA samples reinforced with raw teak wood fibres, Group $C$ reinforced with alkali treated teak wood fibres, Group D reinforced with heat treated teak wood fibres and Group E samples were reinforced with Ultra-High molecular weight (UHMW) polyethylene fibres and processing was carried out by conventional method. The flexural strength of each sample was calculated.

\section{RESULTS}

The mean flexural strength of Group A, Group B, Group C, Group D and Group E were $82.338,58.680,62.259,105.878,90.2263$ respectively with a P value of 0.001 . Group D samples showed a P value $<0.001$ which was statistically significant when compared to other groups. The obtained values were statistically analysed by oneway ANOVA and Tukey's HSD test using statistical software SPSS 17.

\section{CONCLUSIONS}

This in-vitro study infers that the samples of Group D incorporated with heat treated teak fibres had shown increased flexural strength, which could be a good replacement for various synthetic and natural fibres to enhance the strength of denture base resins.

\section{KEY WORDS}

Teakwood Fibres, Heat Treatment, Alkali Treatment, Sandwich Technique, Polyethylene Fibres
Corresponding Author:

Dr. Puja Harie Priya M. S., MDS

Senior Lecturer,

Department of Prosthodontics and

Crown \& Bridge, Ragas Dental College and

Hospital, Uthandi,

Tamilnadu, India.

E-mail: puja19601962@gmail.com

DOI: $10.14260 /$ jemds/2021/420

How to Cite This Article:

Priya MSPH, Jei JB, Krishnan $M$, et al. Evaluation of flexural strength of polymethylmethacrylate denture base resin incorporated with alkali and heat treated teak wood fibers and ultra high molecular weight polyethylene fibers. J Evolution Med Dent Sci 2021;10(28):2051-2055, DOI: $10.14260 /$ jemds/2021/420

Submission 06-03-2021,

Peer Review 11-05-2021,

Acceptance 18-05-2021,

Published 12-07-2021.

Copyright (C) 2021 Puja Harie Priya M. S. et al. This is an open access article distributed under Creative Commons Attribution License [Attribution 4.0 International (CC BY 4.0)] 


\section{BACKGROUND}

Polymethyl methacrylate (PMMA) resin is the most widely used denture base material because it satisfies the aesthetic demands, colour stability, ease of manipulation, accurate fit and also cost effective. ${ }^{1}$ It was introduced by Dr. Walter wright $^{2}$ in the year 1937. Various polymers like polyamides, polystyrene, light activated urethane di methacrylate, poly vinyl acrylic, polycarbonates were used previously, but these materials had not produced accuracy to the dentures. ${ }^{3}$ But there were some disadvantages in PMMA like the adjustments in the occlusal configuration influence denture base twisting and tooth wear which prompts occlusal irregularity, whenever porcelain teeth opposing acrylic teeth, influences the occlusion of the denture it leads to breakage of the denture base. The midline fracture of denture base is mainly due to flexural fatigue failure. ${ }^{4}$ Some authors evidenced problems like air inclusions, incomplete flow, occlusal imbalance, breakage to unsatisfactory impact strength, transverse strength. ${ }^{5}$

In order to improve the mechanical properties like flexural strength, impact strength and fatigue resistance various studies had been conducted using synthetic fibres like polyethylene fibres, polypropylene fibres, aramid fibres, glass fibres, carbon fibres, stainless steel mesh, graphite fibres, and rubber graft copolymer.6,7 But these materials were more expensive and non-renewable. So in this present study ultrahigh molecular weight (UHMW) polyethylene artificial fibres and teak wood natural fibres were incorporated into PMMA. There were only few studies which used natural fibres like sisal fibre, jute fibre, banana fibre, oil palm fruit bunch fibre, hemp fibres, flax fibre and bamboo fibre to reinforce polymer and to enhance their mechanical properties. ${ }^{8}$ These natural fibres are derived from plants, crops, agro - waste, trees etc. and they are cost effective, biodegradable, non-hazardous, biocompatible, non-carcinogenic and renewable. ${ }^{9}$

No previous studies used teak wood fibres, a natural fibre to reinforce PMMA. The teakwood tree with its botanical name of Tectona grandis Linn is one of the tropical hard wood trees, which comes from family Verbenaceae. These fibres have anti - inflammatory, anti-bacterial, antioxidant, antiviral, cytotoxic properties and is ecofriendly. ${ }^{10}$ The UHMW polyethylene fibres are made from polymer or copolymers of olefin hydrocarbon which are thin, strong, and easy to manipulate and exhibit excellent bonding. They can withstand force, pressure, and wear, they are thread like, easy to handle and show good bonding. ${ }^{11}$

Due to natural shade, biocompatibility and low degree compactness combined with its solvent resistant and hydrophobic nature had made them an excellent material in reinforcing denture base resin. Hence in this study teak wood fibres and UHMW polyethylene fibres were used to reinforce the conventional PMMA resin and the flexural strength of each reinforced PMMA resin groups were compared and evaluated.

\section{METHODS}

This comparative in-vitro study was conducted in SRM Dental college, Chennai from April 2017 to December 2018, this study was approved by institutional review board with the IRB approval number SRMDC/IRB/2016/MDS/No.206. According to ISO 20795 - 1 - 2013 three master stainless steel metal dies were prepared with the dimensions of $62 \mathrm{~mm}$ length, $10 \mathrm{~mm}$ width and $3 \mathrm{~mm}$ thickness. The sample size was calculated using single mean-hypothesis testing. Reference article for sample size calculation was based on the study conducted by John et al.

\section{Sample Size Calculation}

Single Mean -Hypothesis testing - one population mean

Standard deviation $=30$

Sample mean $=696$

Population mean $=720$

Alpha Error (\%) $=5 \%$

Power $(\%)=90 \%$

Sided $=2$

Sample size $(\mathrm{n})=16$

Sample size obtained was 16 for each group. So a total of 80 samples were created by using conventional flasking method. They were grouped as

- Group A - Control group (16 samples)

- Group B - incorporated with raw teak wood fibres (16 samples)

- Group C - incorporated with alkali treated teak wood fibres (16 samples)

- Group D - Incorporated with heat treated teak wood fibres (16 samples)

- Group E -Incorporated with UHMW polyethylene fibres (16 samples)

\section{Sample Preparation \\ Group A}

The samples were prepared using heat polymerized PMMA resin according to the manufacturer instructions at a ratio of $1: 3$ by weight the monomer and polymer were mixed. Then flasking and processing was done by conventional method.

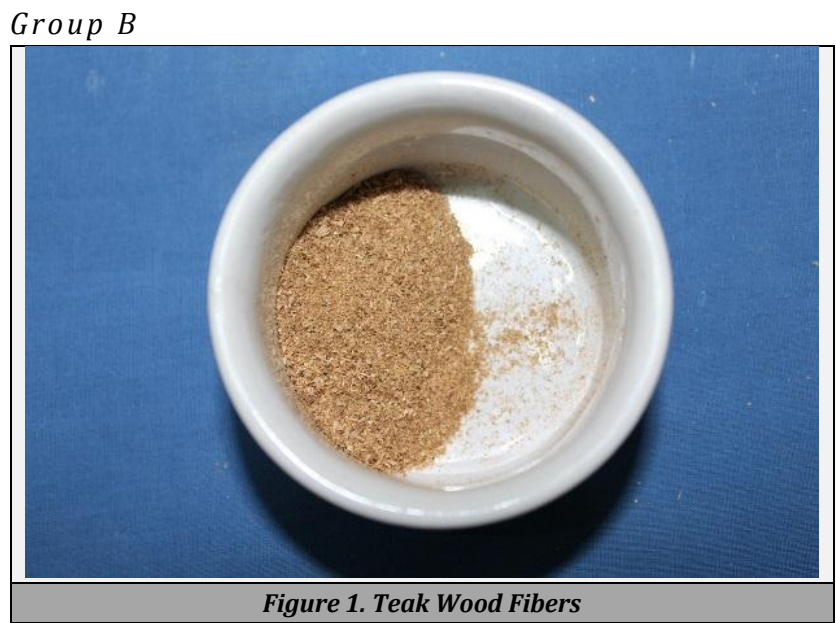

Non - treated dried teak wood fibres (Fig 1) were soaked with monomer in porcelain jar for 10 minutes to improve the adhesion of the fibres with PMMA resin. Then they were removed from monomer and were dried at normal temperature which were then mixed with PMMA resin. In the mold, half of the space was packed with resin and followed by a layer of dried fibres which were placed over the PMMA resin 
and covered to fill the entire mold space. Thus, the fibres were sandwiched between PMMA resin by using sandwich technique.

\section{Group C}

$\mathrm{NaOH}$ alkali solution was used to treat teak wood fibres for 7 days to remove lignin which enhances the surface roughness and that facilitates the mechanical interlocking and bonding of the fibres with PMMA resin. Then the alkali treated fibres were removed from $\mathrm{NaOH}$ solution using mesh screen and was dried in room temperature for 24 hours. Thereafter alkali treated teak wood fibres were soaked in monomer for improved adhesion of the fibres with PMMA resin. PMMA resin was then mixed, and a layer of dried fibres were sandwiched between PMMA resin by using sandwich technique.

\section{Group D}

Dehydration of teakwood fibres was done for 720 mins at $100^{\circ} \mathrm{C}$ in the alumina crucible by placing it inside muffle furnace which was followed by heating at $250^{\circ} \mathrm{C}$ for 24 hours and later it was sintered from $250^{\circ} \mathrm{C}$ to $700^{\circ} \mathrm{C}$ with a heating rate of $2^{\circ} \mathrm{C} / \mathrm{min}$ for 300 mins. Thereafter these fibres were left in the switched off muffle furnace for atmospheric cooling. Then teak wood fibres in the form of powder were added with polymer in mortar and pestle. Then monomer and polymer were mixed in the ratio of $3: 1$.

\section{Group E}

Then UHMW polyethylene fibres were cut into $2 \mathrm{~mm}$ length and $15 \mu \mathrm{m}$ thickness, a total of 2.5 gms of fibres were soaked in $10 \mathrm{ml}$ of monomer for 10 mins for better adhesion of the fibres with acrylic resin. To standardize the procedure $0.5 \mathrm{gms}$ of UHMW polyethylene fibres were added to 10 gms of PMMA to make a sample. Then resin and the fibres were mixed until it was dispersed completely. On reaching the dough stage the mixture was kneaded and packed into the mold space.

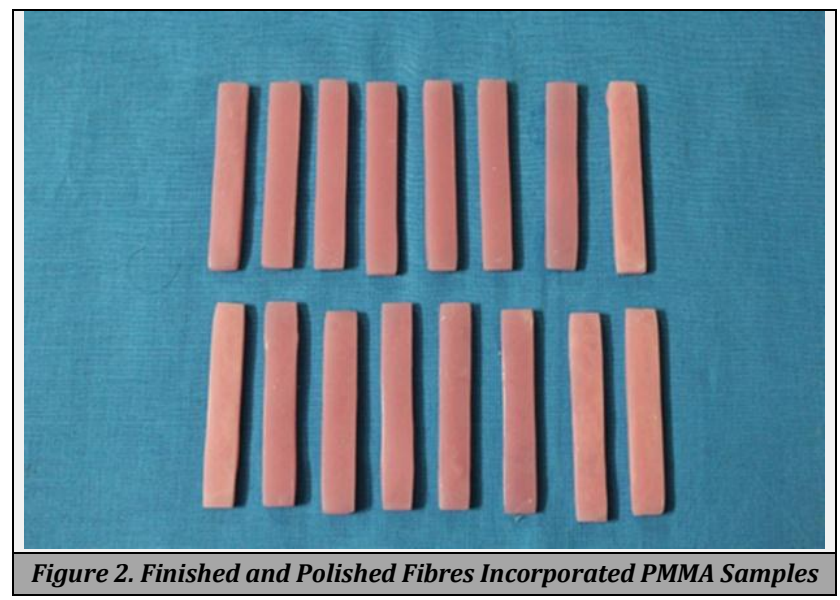

All the acrylic samples prepared by conventional flasking method were retrieved, trimmed, finished, and polished using abrasive and polishing agents (Fig 2). All samples were then stored in water at room temperature until testing. To standardize the procedure 3 samples were prepared by a single operator in a day. The flexural strength of all the samples were tested using 3 - point bending test in a Universal Testing Machine with a span length of $50 \mathrm{~mm}$ and cross - head speed of $(1 \pm 0.3) \mathrm{mm} / \mathrm{min}$ and at the centre of the samples the load was applied until the sample fractured.

\section{Statistical Analysis}

The flexural strength of each sample was calculated, and the obtained values were statistically analysed by one way ANOVA , Tukey's HSD test and post hoc multi-comparison test using SPSS 17 statistical software.

\section{RESULTS}

Table 1 shows the mean and standard deviation values for flexural strength of reinforced and non-reinforced PMMA. The mean flexural strength of Group A, Group B, Group C, Group D and Group E was $82.338+9.645 \mathrm{Mpa}, 58.680+15.611 \mathrm{Mpa}$, $62.258+8.691 \mathrm{Mpa}, 105.878+6.280 \mathrm{Mpa}, 90.226+3.628 \mathrm{Mpa}$ respectively with the significant $P$ value $<0.001$. Among which Group D samples showed a maximum flexural strength value.

\begin{tabular}{|cccccc|}
\hline Groups & $\mathbf{N}$ & Mean & $\begin{array}{c}\text { Std. } \\
\text { Deviation }\end{array}$ & F & Sig. \\
Group A & 16 & 82.3381 & 9.64518 & 66.641 & .000 \\
Group B & 16 & 58.6806 & 15.61067 & & \\
Group C & 16 & 62.2594 & 8.69053 & \\
Group D & 16 & 105.878 & 6.28001 & \\
Group E & 16 & 90.2263 & 3.62886 & \\
Total & $\mathbf{8 0}$ & $\mathbf{7 9 . 8 7 6 6}$ & $\mathbf{2 0 . 0 4 9 1 7}$ \\
\hline Table 1. Mean and Standard Deviations of Flexural Strength of \\
Group A, B, C, D and E and One Way ANOVA of Mean Flexural \\
Strength within the Groups A, B, C, D and E \\
\hline \multicolumn{7}{c}{} \\
\hline
\end{tabular}

The one - way ANOVA of mean values of flexural strength for groups A, B, C, D and E were evaluated. The sum of squares between the groups were 24782.754 and within the groups were 6972.824 The F value was calculated as 66.641 from the mean value. The significant value of $P$ was $<0.001$, hence there was a significant difference in the flexural strength between the groups A, B, C, D and E.

Table 2 describes the Post hoc test or multiple comparison test with significant difference between the Group D, Group E and Group A samples having a mean difference of 23.657 and with $\mathrm{P}$ value $<0.001$. Group $\mathrm{D}$ and $\mathrm{E}$ had a statistically significant value when compared with Group A, B and C.

\begin{tabular}{|c|c|c|c|c|}
\hline (I) Group & (J) Group & $\begin{array}{c}\text { Mean Difference } \\
\text { (I - J) }\end{array}$ & STD. Error & SIG. \\
\hline \multirow{4}{*}{ Group A } & Group B & $23.65750^{\circ}$ & 3.40901 & .000 \\
\hline & Group C & $20.07875^{*}$ & 3.40901 & .000 \\
\hline & Group D & $-23.54063^{\circ}$ & 3.40901 & .000 \\
\hline & Group E & -7.88812 & 3.40901 & .152 \\
\hline \multirow{4}{*}{ Group B } & Group A & $-23.65750^{*}$ & 3.40901 & .000 \\
\hline & Group C & -3.57875 & 3.40901 & .831 \\
\hline & Group D & $-47.19813^{*}$ & 3.40901 & .000 \\
\hline & Group E & $-31.54562^{*}$ & 3.40901 & .000 \\
\hline \multirow{4}{*}{ Group C } & Group A & $-20.07875^{*}$ & 3.40901 & .000 \\
\hline & Group B & 3.57875 & 3.40901 & .831 \\
\hline & Group D & $-43.61938^{*}$ & 3.40901 & .000 \\
\hline & Group E & $-27.96687^{*}$ & 3.40901 & .000 \\
\hline \multirow{4}{*}{ Group D } & Group A & $23.54063^{*}$ & 3.40901 & .000 \\
\hline & Group B & $47.19813^{*}$ & 3.40901 & .000 \\
\hline & Group C & $43.61938^{*}$ & 3.40901 & .000 \\
\hline & Group E & $15.65250^{*}$ & 3.40901 & .000 \\
\hline \multirow{4}{*}{ Group E } & Group A & 7.88812 & 3.40901 & .152 \\
\hline & Group B & $31.54562^{*}$ & 3.40901 & .000 \\
\hline & Group C & $27.96687^{*}$ & 3.40901 & .000 \\
\hline & Group D & $-15.65250^{*}$ & 3.40901 & .000 \\
\hline
\end{tabular}




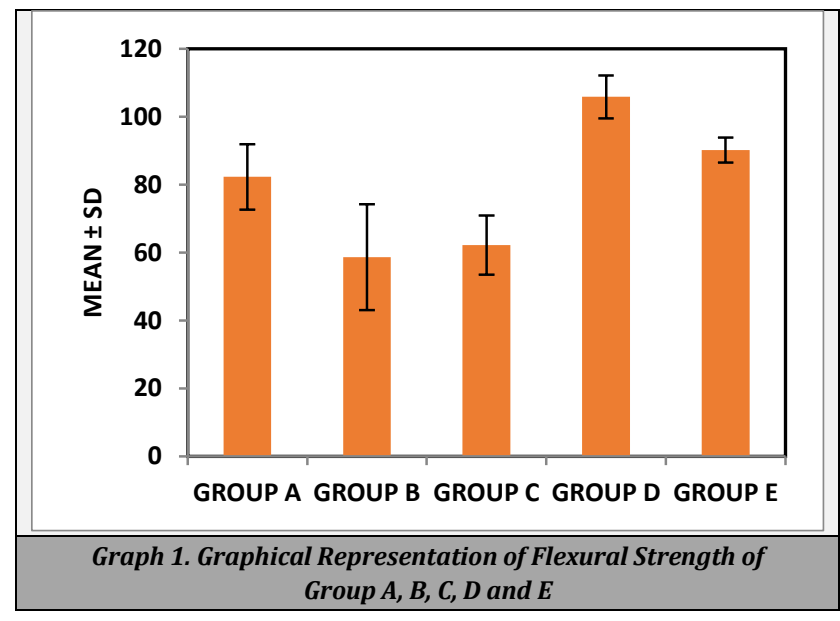

The Graph Showed the mean and standard deviation of all five groups of the study by plotting the measured values on $Y$ axis and Groups on X axis. The mean flexural strength of Group D exhibited higher range of 105.878 followed by Group E, Group A, Group B and Group C which were 90.2263, 82.338, 58.680 and 62.259 respectively.

\section{DISCUSSION}

Although PMMA is known for its poor impact and flexural properties, it is the most frequently used denture base material. ${ }^{8}$ This material may have improper tissue adaptation of the denture leading to fatigue failure which often occurs in midline of the denture bases. ${ }^{12}$ Thus in order to improve its properties many synthetic fibres such as glass, nylon, aramid, polypropylene, carbon, polyethylene, stainless steel mesh, mesh graphite fibres were used. Only fewer studies had used the natural fibres like sisal fibre, jute fibres, banana fibres, oil palm empty fruit bunch fibres, hemp fibres, flax fibres and bamboo fibres for reinforcement of PMMA denture base resin. ${ }^{13,14}$

On incorporation of the natural fibres some authors had found changes in mechanical properties of PMMA reinforced using oil palm empty fruit bunch fibres and this was compared with commercially available PMMA resin. ${ }^{15,16}$ For better adhesion the cellulose and the fibres were soaked in monomer, then dried and added to polymer at dough stage and processing was done by conventional method and concluded that the OPEFB cellulose reinforced specimen had high flexural properties. ${ }^{17}$

The same method was followed in the present study where the raw teak wood fibres were dried and then soaked in monomer for better bonding. The results of present study showed decreased flexural strength which contradicts the above study.

Alkali treatment of the natural fibres play an important role in change in surface structure and composition of the sawdust, that was dipped for 7 days in $2 \% \mathrm{NaOH}$ alkali. ${ }^{18,19}$ And on incorporation into the ceramic membrane the mechanical strength was found to be increased. This method was followed in the present study where the fibres here used with a length of $1 \mathrm{~mm}$ and thickness of $15 \mu \mathrm{m}$ but on comparing the results of the Bose et al. with the present study the results contradict by showing decreased mechanical properties.

Another way of treating the teak wood fibre was by thermal modification, the saw dust of teak wood was dehydrated for 720 mins at $100^{\circ} \mathrm{C}$ in the alumina crucible by placing it inside muffle furnace which was followed by heating at $250^{\circ} \mathrm{C}$ for 24 hours and then it was sintered from $250^{\circ} \mathrm{C}$ to $700^{\circ} \mathrm{C}$ with a heating rate of $2^{\circ} \mathrm{C} / \mathrm{min}$ for 300 mins. Thereafter this sawdust was left in the switched off muffle furnace for atmospheric cooling.

Hence there was increased mechanical strength of ceramic membrane. ${ }^{20,21}$ This method was followed in the present study where the teak wood fibres were used with a length of $1 \mathrm{~mm}$ and thickness of $15 \mu \mathrm{m}$ but on comparing the results of this study with the present study the results coincide by showing improved mechanical properties.

Many authors had used different artificial fibres to enhance the mechanical properties of PMMA. But these artificial ultra-high-modulus polyethylene fibres (UHMPF) were olefin hydrocarbon polymer that were able to withstand the force, pressure, and wear. They were thread like, easy to handle and showed good bonding. Plasma etching was done by placing untreated UHMPE fibre in oxygen chamber which was passed through gas of high voltage discharge which showed improved flexural properties, and hence these fibres were used in the present study. ${ }^{11}$ On comparing the results of the previous study with the present, the results coincided by showing improved flexural properties. This study describes only the raw, alkali treated and heat - treated teak wood fibres and ultra-high-modulus UHMW polyethylene artificial fibre, which were used for reinforcing the PMMA resin. Application of various other surface modification and thermal modifications may influence the outcome of the study.

With the limitations of the present study PMMA resin reinforced with heat treated teak wood fibres showed statistically significant difference with enhanced mean flexural strength when compared to no reinforced, reinforced with raw, alkali treated teak wood fibres and UHMW polyethylene fibre.

\section{CONCLUSIONS}

Within the limitations of the study it was concluded that flexural strength of acrylic denture base resin can be enhanced by incorporating heat treated teak wood fibers. As teak wood fibers are easily available, less in cost, with antimicrobial and anti-inflammatory properties this could be clinically applicable as an alternate to other artificial and natural fibres for strengthening partial and completely PMMA dentures.

Data sharing statement provided by the authors is available with the full text of this article at jemds.com.

Financial or other competing interests: None.

Disclosure forms provided by the authors are available with the full text of this article at jemds.com. 


\section{REFERENCES}

[1] Beyli MS, Von Fraunhofer JA. An analysis of causes of fracture of acrylic resin dentures. J Prosthet Dent 1981;46(3):238-41.

[2] Peyton FA. History of resins in dentistry. Dent Clin North Am 1975;19(2):211-22.

[3] Tallgren A. The continuing reduction of the residual alveolar ridges in complete denture wearers: a mixedlongitudinal study covering 25 years. J Prosthet Dent 1972;27(2):120-32.

[4] Bansal A, Kumosa M. Application of the biaxial Iosipescu method to mixed-mode fracture of unidirectional composites. Int J Fract 1995;71(2):131-50.

[5] Yazdanie N, Mahood M. Carbon fiber acrylic resin composite: an investigation of transverse strength. J Prosthet Dent 1985;54(4):543-7.

[6] John J, Gangadhar SA, Shah I. Flexural strength of heatpolymerized poly methyl methacrylate denture resin reinforced with glass, aramid or nylon fibers. J Prosthet Dent 2001;86(4):424-7.

[7] Dagar SR, Pakhan AJ, Thombare RU, et al. The evaluation of flexural strength and impact strength of heatpolymerized polymethyl methacrylate denture base resin reinforced with glass and nylon fibers: an in vitro study. J Indian Prosthodont Soc 2008;8(2):98-104.

[8] Cheng YY, Li JY, Fok SL, et al. 3D FEA of high-performance polyethylene fiber reinforced maxillary dentures. Dent Mater 2010;26(9):211-9.

[9] Krishna MS, Nair AJ. Antibacterial, cytotoxic and antioxidant potential of different extracts from leaf, bark and wood of tectona grandis. Int J Pharm Sci Drug Res 2010;2(2):155-8.

[10] Alla RK, Sajjan S, Alluri VR, et al. Influence of fiber reinforcement on the properties of denture base resins. J Biomater Nanobiotechnol 2013;4(1):91-7.
[11] Gutteridge DL. Reinforcement of poly (methyl methacrylate) with ultra-high-modulus polyethylene fibre. J Dent 1992;20(1):50-4.

[12] John J, Mani SA, Palaniswamy K, et al. Flexural properties of poly (methyl methacrylate) resin reinforced with oil palm empty fruit bunch fibers: a preliminary finding. J Prosthodont 2015;24(3):233-8.

[13] Bose S, Sawdust DC. From wood waste to pore-former in the fabrication of ceramic membrane. Ceram Int 2015;41(1):4070-9.

[14] Kabir MM, Wang H, Lau KT, et al. Chemical treatments on plant-based natural fibre reinforced polymer composites: an overview. Composites Part B: Engineering 2012;43(7):2883-92.

[15] Nidavani RB, Mahalakshmi AM. Teak (Tectona grandis Linn.): a renowned timber plant with potential medicinal values. Inter J Pharm Pharm Sci 2014;6(1):48-54.

[16] Kelly E. Fatigue failure in denture base polymers. J Prosthet Dent 1969;21(3):257-66.

[17] Lambrecht JR, Kydd WL. A functional stress analysis of the maxillary complete denture base. J Prosthet Dent 1962;12(5):865-72.

[18] Patil YP, Gajre B, Dusane D, et al. Effect of maleic anhydride treatment on steam and water absorption of wood polymer composites prepared from wheat straw, cane bagasse and teak wood sawdust using novolac as matrix. J Appl Polym Sci 2000;77(13):2963-7.

[19] Thomas TC, Kumar A, Mohamed S, et al. The effect on the flexural strength, flexural modulus and compressive strength of fibre reinforced acrylic with that of plain unfilled acrylic resin-an in vitro study. J Clin Diagn Res 2015;9(3):ZC12-4.

[20] Sajith S, Arumugam V, Dhakal HN. Comparison on mechanical properties of lignocellulosic flour epoxy composites prepared by using coconut shell, rice husk and teakwood as fillers. Polym Test 2017;58:60-9.

[21] Xu J, Li Y, Yu T, Cong L. Reinforcement of denture base resin with short vegetable fiber. Dent Mater 2013;29(12):1273-9. 